\title{
Adherence to antihypertensive treatment and associated factors among patients on follow up at University of Gondar Hospital, Northwest Ethiopia
}

\author{
Abere Dessie Ambaw ${ }^{1}$, Getahun Asres Alemie², Solomon Meseret W/Yohannes ${ }^{2}$ and Zelalem Birhanu Mengesha ${ }^{3^{*}}$
}

\begin{abstract}
Background: Hypertension is an overwhelming global challenge with high morbidity and mortality rates. The prevalence of HTN is estimated to be $6 \%$ in Ethiopia and 30\% in Addis Ababa. Poor adherence is associated with bad outcome of the disease and wastage of healthcare resources. In Ethiopia, particularly in the study area little is known about treatment adherence and associated factors. Therefore this study aimed to assess adherence to antihypertensive therapy and associated factors among HTN patients on follow up at University of Gondar Referral Hospital.

Method: Institution based cross sectional study was conducted. Systematic sampling technique was used to select 384 participants. A structured standard questionnaire was used after some modifications. Morisky Medication Adherence Scale was used for labeling patients as adherent or non-adherent. Data were entered and analyzed using SPSS version 16.

Results: More than half (64.6\%) of the study participants were found to be adherent to their treatment. Sex $(A O R=0.48,95 \% \mathrm{Cl}=0.28,0.82)$, knowledge about HTN and its treatment $(A O R=6.21,95 \% \mathrm{Cl}=3.22,11.97)$, distance from the hospital $(A O R=2.02,95 \% \mathrm{Cl}=1.19-3.43)$ and co morbidity $(A O R=2.5,95 \% \mathrm{Cl}=1.01,6.21)$ variables were found significantly associated with treatment adherence.

Conclusion: Only $64.6 \%$ of the study subjects were found to be adherent to their treatment. Factors such as sex, distance from the hospital, number of co morbidities, Knowledge about HTN and its treatment were associated with adherence behavior of patients. Early diagnosis and management of co morbidities, adherence counseling and patient education about the disease and its treatment are important to improve adherence status of patients.
\end{abstract}

\section{Background}

Hypertension (HTN), or high blood pressure (systolic blood pressure $\geq 140 \mathrm{mmHg}$ and diastolic blood pressure $\geq 90 \mathrm{mmHg}$ ) is an overwhelming global challenge which ranks third as a cause of disabilityadjusted life-year [1]. Hypertension causes 7.1 million premature deaths each year worldwide and accounts for $13 \%$ of all deaths globally [2]. Analysis of the global burden of hypertension revealed that over $26 \%$ of the world's adult population had hypertension in 2000 [3]. In developing countries, its morbidity and mortality are increasing from time to time due to a

\footnotetext{
*Correspondence: zelalem78@gmail.com

${ }^{3}$ Department of Reproductive Health, Institute of Public Health,

University of Gondar, Gondar, P.O.Box 196, Ethiopia

Full list of author information is available at the end of the article
}

change in life style and sedentary life. In Africa, $15 \%$ of the population has hypertension [4]. Although there is shortage of extensive data, $6 \%$ of the Ethiopian population has been estimated to have HTN. Approximately $30 \%$ of adults in Addis Ababa have hypertension above $140 / 90 \mathrm{mmHg}$ or reported use of anti-hypertensive medication [5].

There are effective medical therapies for hypertension management. However, only $37 \%$ of hypertensive patients in a 2003-2004 survey were reported to have their blood pressure controlled [6]. The problem of non-adherence to medical treatment remains a challenge for the medical professions and social scientists. As a result, substantial numbers of patients do not get the maximum benefit of medical treatment, resulting in poor health outcomes, lower quality of life and increased health care costs. In 
spite of many advances made in adherence research, nonadherence rates have remained nearly unchanged in the last decades $[1,7,8]$.

Poor adherence to anti-hypertensive therapy is one of the biggest obstacles in therapeutic control of high blood pressure [6]. It also compromises the efforts of the health care system, policy makers and health care professionals in improving the health of populations. Failure to adhere causes medical and psychological complications of the disease, reduces patients' quality of life, wastes health care resources and erodes public confidence in health systems [9].

Poor adherence to anti-hypertensive therapy is usually associated with bad outcome of the disease and wastage of limited health care resources. In Ethiopia, particularly in the study area, little is known about the adherence status and associated factors. Therefore, the aim of this study was to assess the adherence status and associated factors to antihypertensive therapy among patients on follow up at University of Gondar Hospital.

\section{Methods}

Institution based cross-sectional survey was done at University of Gondar teaching Hospital from April to August 2011. The University of Gondar Teaching Hospital is located in Gondar Town, Amhara National Regional State, Ethiopia. The Town consisted of one central referral Hospital and three health centers. Gondar University Hospital is a teaching as well as regional referral Hospital under ministry of education. The situation in Ethiopia is that most of the Hospitals where Universities are located are teaching referral Hospitals. The referral Hospital is meant to serve 5 million people as per the four tier system of the National Ministry of Health. Chronic illness care is one of the services the Hospital provides to the population both within and outside of Gondar Town. Provision of treatments for hypertensive patients is one of the chronic illnesses included in the chronic illness care. There were 968 patients on antihypertensive treatment at the chronic illness follow-up care. The study was conducted among hypertensive patients of age 18 years and above receiving antihypertensive treatment as outpatients at the University of Gondar Referral Hospital. A single population proportion formula, $\left[n=(Z \alpha / 2)^{2} p(1-p)\right]$, was used to estimate the sample size. The following assumptions were made: since no previous data, proportion was taken as 50\% $(p=0.5), 95 \%$ confidence interval, margin of error $5 \%$ $(d=0.05)$. Computing with the above formula gives a total sample size of 384. Every other 2 patients were interviewed when they come for follow up at the chronic care clinic using systematic random sampling technique from the registration list of patients.

\section{Controlled hypertension}

Average BP reading less than $140 / 90 \mathrm{mmHg}$ at the time of data collection irrespective of measurements at other times.

\section{Knowledgeable}

Respondents who scored above mean for the knowledge questions.

\section{Good patient-provider relationship}

Participants who scored mean and above for questions prepared on patient provider relationship in the treatment and care of HTN patients otherwise not. A standard pretested questionnaire supplemented with patient medical record review to counter check the clinical data reports was used. Data were collected by trained nurses working in the other wards of the hospital. Additional two nurses were assigned to supervise the data collection process. Morisky Medication Adherence Scale (MMAS), a 4-item questionnaire with a high reliability and validity, which has been particularly useful in chronic conditions such as hypertension was used [10]. The scale is based on patient's self response [11]. The total score ranges from 1 to 5. During analysis, a cut-off value of MMAS mean score $>=3$ and $<3$ were used for labeling patients as adherent or non-adherent respectively [12].

After participants are interviewed, two sitting BP measurements were taken in the right arm with pre-tested mercury/aneroid sphygmomanometers and stethoscopes approximately $2 \mathrm{~min}$ apart and the average of the two readings were used to determine the $\mathrm{BP}$ level. The cuff size was $23 \times 12.5 \mathrm{~cm}$. For all readings Korotkoff phases I and $\mathrm{V}$ were used to establish the levels of systolic and diastolic blood pressure, respectively.

The data were entered and analyzed using SPSS version 16 statistical package. Data cleaning was performed to check for accuracy, consistency and there were no missed values during entry. Frequencies, proportions and summary statistics were used to describe the study population in relation to relevant variables. Bivariate and multivariate analyses were carried out to see the putative associations of each independent variable with the dependent variable. Odds ratio and 95\% confidence interval were also used to identify the presence and strength of association.

Ethical approval from the institutional review board of the University of Gondar was obtained. Permission to conduct the study in follow-up unit was obtained from the medical director's office of the hospital. Each study participant was adequately informed about the purpose, method, anticipated benefit and risk of the study by the data collectors. Verbal consent was obtained from study participants and anonymity was maintained to ensure confidentiality. 


\section{Results}

Socio-demographic characteristics

A total of 384 study participants were interviewed making the response rate $100 \%$. The mean age of respondents was 56.9 years with a standard deviation of 12.8. Orthodox Christians and the Amhara ethnic group accounted for $89.3 \%$ and $94 \%$ of the respondents respectively. More than three fourth $(76.6 \%)$ of the respondents were urban by resident. Two hundred thirty three (60.7\%) reported to be married and $93(24.2 \%)$ were merchants. For two hundred thirty three (60.7\%), it takes half an hour and above on single trip to reach to the hospital. (Table 1)

Table 1 Socio demographic characteristic of the study

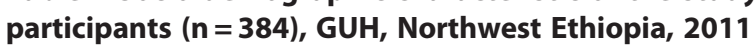

\begin{tabular}{|c|c|c|c|}
\hline Variables & & Frequency & Percent (\%) \\
\hline \multirow[t]{2}{*}{ Sex } & Male & 142 & 37.0 \\
\hline & Female & 242 & 63.0 \\
\hline \multirow[t]{3}{*}{ Age } & $18-40$ & 36 & 9.4 \\
\hline & $41-60$ & 210 & 54.7 \\
\hline & $>=60$ & 138 & 35.9 \\
\hline \multirow[t]{3}{*}{ Ethnicity } & Amhara & 361 & 94.0 \\
\hline & Tigrie & 18 & 4.7 \\
\hline & Others & 5 & 1.3 \\
\hline \multirow[t]{2}{*}{ Residence } & Rural & 90 & 23.4 \\
\hline & Urban & 294 & 76.6 \\
\hline \multirow[t]{4}{*}{ Marital status } & Single & 17 & 4.4 \\
\hline & Married & 233 & 60.7 \\
\hline & Divorced & 41 & 10.7 \\
\hline & Widowed & 93 & 24.2 \\
\hline \multirow[t]{3}{*}{ Religion } & Orthodox & 343 & 89.3 \\
\hline & Muslim & 36 & 9.4 \\
\hline & Others & 5 & 1.3 \\
\hline \multirow[t]{6}{*}{ Employment status } & Government & 74 & 19.3 \\
\hline & Merchant & 93 & 24.2 \\
\hline & Student & 8 & 2.1 \\
\hline & Housewife & 87 & 22.7 \\
\hline & Farmer & 43 & 11.2 \\
\hline & Retired & 79 & 20.6 \\
\hline \multirow[t]{4}{*}{ Educational status } & $\begin{array}{l}\text { Cannot read } \\
\text { and write }\end{array}$ & 196 & 51 \\
\hline & Grade 1-6 & 60 & 15.6 \\
\hline & Grade 7-12 & 83 & 21.6 \\
\hline & $\begin{array}{l}\text { Diploma and } \\
\text { above }\end{array}$ & 45 & 11.7 \\
\hline \multirow[t]{3}{*}{ Monthly income } & $<500$ ETB & 248 & 64.6 \\
\hline & 500-1000ЕТВ & 65 & 16.9 \\
\hline & $>=1000 \mathrm{ETB}$ & 71 & 18.5 \\
\hline \multirow{2}{*}{$\begin{array}{l}\text { Distance from the } \\
\text { hospital(single trip) }\end{array}$} & $<0.5 \mathrm{~h}$ & 151 & 39.3 \\
\hline & $>0.5 \mathrm{~h}$ & 233 & 60.7 \\
\hline
\end{tabular}

Clinical, medication and adherence characteristics

Near half (47.4\%) of the respondents had no any of the co morbidities like heart disease, diabetes mellitus, renal diseases and others. More than half (53.4\%) of the study subjects had uncontrolled blood pressure. Regarding the medication information, 154 (40.1\%) of the subjects have been taking only one drug while $45.3 \%$ and $14.6 \%$ of them were on two and three and above $(\geq 3)$ drugs, respectively. Regarding the cost of medication, $59.6 \%$ of the respondents were getting their medication for free. In addition, data were also collected on the duration of treatment. Accordingly, 135 (35.2\%) of them have been taking their treatment for the last 2 to 4 years. The mean number of pills taken per day was 2.5 with standard deviation of 1.4 (Table 2).

Table 2 Medication and Blood pressure characteristic of respondents, GUH, Northwest Ethiopia, 2011

\begin{tabular}{|c|c|c|}
\hline Variables & Frequency & Percent \\
\hline \multicolumn{3}{|l|}{ Number of co morbidity } \\
\hline None & 182 & 47.4 \\
\hline 1 & 170 & 44.3 \\
\hline$>=2$ & 32 & 8.3 \\
\hline \multicolumn{3}{|l|}{ Blood pressure: } \\
\hline Controlled & 179 & 46.6 \\
\hline Uncontrolled & 205 & 53.4 \\
\hline \multicolumn{3}{|l|}{ Number of drugs: } \\
\hline One & 154 & 40.1 \\
\hline Two & 174 & 45.3 \\
\hline Three and above & 56 & 14.6 \\
\hline \multicolumn{3}{|l|}{ Dosage: } \\
\hline Once daily & 179 & 46.6 \\
\hline $\mathrm{BID}$ & 196 & 51.0 \\
\hline TID and above & 9 & 2.3 \\
\hline \multicolumn{3}{|l|}{ Number of pills per day: } \\
\hline One pill & 112 & 29.2 \\
\hline Two pills & 99 & 25.8 \\
\hline Three pills & 101 & 26.3 \\
\hline Four and above pills & 72 & 18.8 \\
\hline \multicolumn{3}{|c|}{ Who covered the cost of the drug? } \\
\hline Myself & 128 & 33.3 \\
\hline Family & 12 & 3.2 \\
\hline Free & 229 & 59.6 \\
\hline Employer organization & 15 & 3.9 \\
\hline \multicolumn{3}{|c|}{ Duration of treatment in yrs: } \\
\hline $0.25-1$ yrs & 109 & 28.4 \\
\hline $2-4$ yrs & 135 & 35.2 \\
\hline $5-7$ yrs & 55 & 14.3 \\
\hline $8-10 \mathrm{yrs}$ & 42 & 10.9 \\
\hline$\geq 11 \mathrm{yrs}$ & 43 & 11.2 \\
\hline
\end{tabular}


Only $64.6 \%$ of the study subjects were found to be adherent to their treatment. Majority of the respondents (76.8\%) were knowledgeable about HTN and its treatment.

\section{Factors associated with antihypertensive treatment adherence}

The association of selected socio-demographic, clinical and other characteristics on adherence status was investigated using both the bivariate and multivariate logistic regression technique. Accordingly, variables considered in the bivariate analysis were: age, sex, residence, marital status, religion, educational status, income, employment status, number of co-morbidities, BP level, distance, dosage frequency, duration of treatment, number of medications, coverage of drug cost, knowledge about HTN and Patient provider relationship. Explanatory variables with $\mathrm{p}$ value up to 0.2 were included in the multiple logistic regressions. Finally, sex, distance $<0.5 \mathrm{~h}$ from the hospital, having no or one co-morbidity, having controlled BP, being knowledgeable about HTN remained to be significantly associated with adherence to treatment of HTN. (Table 3)

The multivariate logistic regression showed that as the distance from the hospital decreased, the adherence to treatment of HTN got improved $(\mathrm{AOR}=2.02,95 \% \mathrm{CI}=$ $1.19,3.43)$. Those who have controlled HTN had a significantly higher chance of being adherent to their treatment $(\mathrm{AOR}=2.93,95 \% \mathrm{CI}(1.73,4.96)$. The odds of adherence to anti-HTN treatment among knowledgeable Clients was 6 times $(\mathrm{AOR}=6.21,95 \% \mathrm{CI}=3.22,11.97)$ higher than the odds of adherence among HTN patients who were not knowledgeable. The odds of adherence among study participants with no or one co-morbidity were 2.5 and 2.68 times higher than the odds adherence among those who had two co-morbidities (adjusted $\mathrm{OR}=2.50,95 \% \mathrm{CI} 1.01$, 6.21 ) or more than two co-morbidities (adjusted $\mathrm{OR}=2.68$, $95 \%$ CI 1.07, 6.71), respectively.

\section{Discussion}

Ensuring patients' adherence to anti hypertension medications to prevent complications of hypertension remains a major challenge to public health in many developing countries. Poor adherence to treatment is the single most important reason for uncontrolled hypertension, serious complications and wastage of health care resources. Several factors, which may be patient or health system related, continue to militate against compliance behavior $[9,13]$.

Only $64.6 \%$ of the study subjects were found to be adherent to their treatment. It is higher than what has been reported from Malaysia (44.2\%) and Gambia 27\% [10,14]. The adherence to antihypertensive treatment found in the current study was also higher than that of $57 \%$ found in the study done in Pakistan [15]. This difference is possibly because more than half $(59.6 \%)$ of the patients in the current study receive free medical care and drugs whereas in the other study patients had to pay for their treatment. However, it is lower than the studies done in Egypt (74.1\%), another part of Pakistan (77\%) and Scotland $(91 \%)[8,12,16]$. This might be due to better access and care to patients in these countries. It is also supported by the findings of this study that, for $71.3 \%$ of the non adherents, the hypertension treatment and care service was not accessible.

In this study, significant association between sex and adherence level was observed. Accordingly, men were found to be less adherent when compared to women. This finding is in line with a study done in India [12], where men had almost threefold increase in risk of nonadherence as compared to women. This can be explained by the fact that; men are burdened by the outdoor activities which make them busy and make them forget their medications. Alcohol consumption, a commonly practice by males, could also be a barrier for their treatment adherence.

Longer distance was a big barrier for adherence to treatment recommendations especially when it was accompanied by poor infrastructure (e.g. lack of transportation) and poverty. Distance from the hospital was another variable found to be significantly and independently associated with the adherence status of the respondents. Those patients from distant areas were less likely to be adherent as compared to study subjects who are closer. This finding is supported by the study done in India [12]. Patients who take long to come to the clinic have certain characteristics that promote non-adherence, which also delayed them from coming for review and possibly collecting drugs from the hospital when they refill the antihypertensive.

Co-morbidities can worsen the conditions of the patient and make them unable to adhere to their antihypertensive medications. This study revealed that the numbers of co morbidities among HTN patients had significant associations on adherence behavior. Patients with no and one co morbidities were more likely to adhere to their treatment than those with two and above co morbidities. Patients with more number of co morbidities could suffer from serious complications and complex treatment regimens which were favorable conditions not to adhere to their medications.

Right knowledge about HTN and its treatment creates a clear understanding and avoids confusion about the treatment and the disease condition. Knowledge about HTN and its treatment was found to be positively associated with adherence behavior. Patients with better awareness were more likely to adhere to their treatment. A similar study from Pakistan and Gaza demonstrated that patients who were aware of their diseases and treatments had 
Table 3 Effect of selected socio-demographic, clinical and other characteristics on adherence to antihypertensive treatment, GUH, Northwest Ethiopia, 2011

\begin{tabular}{|c|c|c|c|c|c|}
\hline \multirow[t]{2}{*}{ Variables } & & \multicolumn{2}{|c|}{ Adherence Status } & \multirow[t]{2}{*}{$\operatorname{COR}(95 \% \mathrm{Cl})$} & \multirow[t]{2}{*}{ AOR $(95 \% \mathrm{Cl})$} \\
\hline & & Adheren & Non adherent & & \\
\hline \multirow[t]{2}{*}{ Sex } & Male & 87 & 55 & $0.80(0.51,1.22)$ & $0.48(0.28,0.82)^{* *}$ \\
\hline & Female & 161 & 81 & 1 & 1 \\
\hline \multirow[t]{2}{*}{ Residence } & Rural & 51 & 39 & 1 & \\
\hline & Urban & 197 & 97 & $1.55(0.96,2.52) *$ & \\
\hline \multirow[t]{4}{*}{ Marital Status } & Single & 13 & 4 & 1 & \\
\hline & Married & 157 & 76 & 0.64 & $(0.20,2.02) *$ \\
\hline & Divorced & 22 & 19 & 0.36 & $(0.10,1.28)^{*}$ \\
\hline & Widowed & 56 & 37 & 0.47 & $(0.14,1.52) *$ \\
\hline \multirow[t]{2}{*}{ Religion } & Orthodox & 226 & 117 & $0.60(.31,1.15)^{*}$ & \\
\hline & Others & 22 & 19 & 1 & \\
\hline \multirow[t]{4}{*}{ Educational status } & Illiterate & 119 & 77 & 1 & \\
\hline & Grade 1-6th & 39 & 21 & $1.20(0.66,2.20) *$ & \\
\hline & Grade 7-12th & 58 & 25 & $1.50(0.87,2.60) *$ & \\
\hline & Diploma and above & 32 & 13 & $1.59(0.79,3.23)^{*}$ & \\
\hline \multirow[t]{5}{*}{ Income level } & $<=500 \mathrm{ETB}$ & 152 & 96 & 1 & \\
\hline & 501-100 ETB & 39 & 26 & $0.95(0.54,1.66)^{*}$ & \\
\hline & $>=1001 \mathrm{ETB}$ & 57 & 14 & $2.57(1.36,4.87)^{*}$ & \\
\hline & Government worker & 56 & 18 & $1.80(0.90,3.64)^{*}$ & \\
\hline & Merchant & 54 & 39 & $0.8(0.43,1.49) *$ & \\
\hline \multirow[t]{4}{*}{ Employment status } & Student & 6 & 2 & $1.74(0.33,9.19)^{*}$ & \\
\hline & House wife & 57 & 30 & $1.10(0.58,2.08)^{*}$ & \\
\hline & Farmer & 25 & 18 & $0.81(0.38,1.72)^{*}$ & \\
\hline & Retired & 50 & 29 & & \\
\hline \multirow[t]{3}{*}{ No of co morbidities } & None & 118 & 64 & $2.09(0.98,4.46)$ & $2.50(1.01,6.21)^{* *}$ \\
\hline & One & 115 & 55 & $2.37(1.10,5.09)$ & $2.68(1.07,6.71)^{* *}$ \\
\hline & Two and above & 15 & 17 & 1 & 1 \\
\hline \multirow[t]{2}{*}{ BP level } & Controlled & 136 & 43 & $2.63(1.69,4.08)$ & $2.93(1.73,4.96)^{* *}$ \\
\hline & Uncontrolled & 112 & 93 & 1 & 1 \\
\hline \multirow[t]{2}{*}{ Distance in hrs } & $<0.5$ hrs & 112 & 39 & $2.05(1.31,3.21)$ & $2.02(1.19,3.43)^{* *}$ \\
\hline & $\geq 0.5 \mathrm{hrs}$ & 136 & 97 & 1 & 1 \\
\hline \multirow[t]{3}{*}{ Dosage frequency } & Once daily & 123 & 56 & $1.10(0.27,4.55)^{*}$ & \\
\hline & $\mathrm{BID}$ & 119 & 77 & $0.77(0.19,3.18)^{*}$ & \\
\hline & TID and above & 6 & 3 & 1 & \\
\hline Knowledge towards & Knowledgeable & 224 & 71 & $8.55(4.99,14.65)$ & $6.21(3.22,11.97)^{* *}$ \\
\hline HTN and its treatment & Not Knowledgeable & 24 & 65 & 1 & 1 \\
\hline \multirow[t]{2}{*}{ Attitude } & Favourable & 236 & 96 & $8.19(4.12,16.29)$ & $3.23(1.31,7.97)^{* *}$ \\
\hline & Not favourable & 12 & 40 & 1 & 1 \\
\hline \multirow[t]{2}{*}{ Pt-provider relationship } & Good & 239 & 124 & $2.57(1.05,6.27)^{*}$ & \\
\hline & Poor & 9 & 12 & 1 & \\
\hline
\end{tabular}

Note: - ** statistically significant * variables with $\mathrm{p}$ value of greater than 0.2 in crude analysis omitted from entering in to the model.

better adherence compared to those who did not [17]. However, in contrast to this finding, studies from some developed world indicated no association between knowledge and adherence $[18,19]$.
In this study, blood pressure control level was associated with adherence behavior. Those with controlled blood pressure were observed to be adherent. This finding is in line with the study done in Greece [19]. It might 
be attributable to better outcome of the treatment, may offer the patient good satisfactions and creates strong motivation towards the treatment. However, bad outcome (uncontrolled BP) could make the patient hopeless and low satisfaction and hence urged them to stop their treatment.

\section{Conclusions}

In conclusion, more than half of the study participants were found to be adherent to their treatment. Factors such as sex, distance from the hospital, number of co morbidities, Knowledge about HTN and its treatment were associated with adherence behavior of patients. Early diagnosis and management of co morbidities, adherence counseling and patient education about the disease and its treatment are important to improve adherence status of patients.

This study have the following limitations: self-reporting was used as the only method of measuring adherence. This method has the disadvantages of recall bias and eliciting only socially acceptable responses and hence, may overestimate the level of adherence. In addition, it did not consider HTN patients who did not visit the hospital during the time of the study. Hence, the extent of generalisability is limited only to those similar patients who are on chronic illness follow up care.

\section{Competing interests}

The authors declare that they have no competing interests.

\section{Acknowledgements}

We are very grateful to the University of Gondar for the approval of the ethical clearance and for their technical support of this study. Then, we would like to thank all patients who participated in this study for their commitment in responding to our interviews.

\section{Author details}

'College of Medicine and Health Sciences, University of Gondar, Gondar, P.O. Box 196, Ethiopia. ${ }^{2}$ Department of Epidemiology and Biostatistics, Institute of Public Health, University of Gondar, Gondar, P.O.Box 196, Ethiopia. ${ }^{3}$ Department of Reproductive Health, Institute of Public Health, University of Gondar, Gondar, P.O.Box 196, Ethiopia.

\section{Authors' contributions}

AD wrote the proposal, participated in data collection, analyzed the data and drafted the paper. GA, SM and ZB approved the proposal with some revisions, participated in data analysis and revised subsequent drafts of the paper. All authors read and approved the final manuscript.

Received: 9 January 2012 Accepted: 10 April 2012

Published: 10 April 2012

\section{References}

1. Kearney PM, Whelton M, Reynolds K, Muntner P, Whelton PK, He J: Global burden of hypertension: analysis of worldwide data. Lancet 2005, 365 (9455):217-223.

2. Chobanian AV, Bakris GL, Black HR, Cushman WC, Green LA, Izzo JL Jr: Jones DW, Materson BJ, Oparil S, Wright JT Jr, et al: Seventh report of the Joint National Committee on Prevention, Detection, Evaluation, and Treatment of High Blood Pressure. Hypertension 2003, 42(6):1206-1252.

3. Hajjar I, Kotchen TA: Trends in prevalence, awareness, treatment, and control of hypertension in the United States, 1988-2000. JAMA 2003, 290 (2):199-206.
4. Salako LA: Hypertension in Africa and Effectiveness of Its Management with Various Classes of Antihypertensive Drugs and in Different SocioEconomic and Cultural Environments. Clin Exp Hypertens 1993, 15(6):9971004.

5. Tesfaye $F$, Byass $P$, Wall S: Population based prevalence of high blood pressure among adults in Addis Ababa: uncovering a silent epidemic. BMC Cardiovasc Disord 2009, 9(39).

6. Ong KL, Cheung BMY, Man YB, Lau CP, Lam KSL: Prevalence, Awareness, Treatment, and Control of Hypertension Among United States Adults 1999-2004. Hypertension 2006, 49:69-75.

7. Primatesta P, Poulter NR: Improvement in hypertension management in England: results from the Health Survey for England 2003. $J$ Hypertens 2006, 24(6):1187-1192.

8. Hashmi SK, Afridi MB, Abbas K, Sajwani RA, Saleheen D, Frossard PM, Ishaq M, Ambreen A, Ahmad U: Factors associated with adherence to antihypertensive treatment in Pakistan. PLoS One 2007, 2(3):e280.

9. Balkrishnan $\mathrm{R}$ : The importance of medication adherence in improving chronic-disease related outcomes: what we know and what we need to further know. Med Care 2005, 43(6):517-520.

10. Morisky DE, Green LW, Levine DM: Concurrent and predictive validity of a self-reported measure of medication adherence. Med Care 1986, 24(1):6774.

11. Pratt RJ, Robinson N, Loveday HP, Pellowe CM, Franks PJ, Hankins M, Loveday C: Adherence to Antiretroviral Therapy: Appropriate Use of SelfReporting in Clinical Practice. HIV Clin Trials 2001, 2(2):146-159.

12. Inkster ME, Donnan PT, MacDonald TM, Sullivan FM, Fahey T: Adherence to antihypertensive medication and association with patient and practice factors. J Hum Hypertens 2006, 20(4):295-297.

13. Kearney PM, Whelton M, Reynolds K, Whelton PK, He J: Worldwide prevalence of hypertension: a systematic review. J Hypertens 2004, 22 (1):11-19.

14. van der Sande MA, Milligan PJ, Nyan OA, Rowley JT, Banya WA, Ceesay SM, Dolmans WM, Thien T, McAdam KP, Walraven GE: Blood pressure patterns and cardiovascular risk factors in rural and urban gambian communities. $J$ Hum Hypertens 2000, 14(8):489-496.

15. Lennon C, Hughes CM, Mcelnay JC, Johnston GD: Identification of psychosocial factors which influence patient adherence with antihypertensive medication. Int J Pharm Pract 2001, 9(s1):8.

16. Rm Y: II M: Patterns and determinants of treatment compliance among hypertensive patients. East Mediterr Health J 2002, 8(4-5):579-592.

17. Baune B, Aljeesh Y: The association of psychological stress and health related quality of life among patients with stroke and hypertension in Gaza Strip. Ann Gen Psychiatr 2006, 5(6).

18. Krousel-Wood M, Thomas S, Muntner P, Morisky D: Medication adherence: a key factor in achieving blood pressure control and good clinical outcomes in hypertensive patients. Curr Opin Cardiol 2004, 19(4):357-362.

19. Yiannakopoulou E, Papadopulos JS, Cokkinos DV, Mountokalakis TD: Adherence to antihypertensive treatment: a critical factor for blood pressure control. Eur J Cardiovasc Prev Rehabil 2005, 12(3):243-249.

\section{doi:10.1186/1471-2458-12-282}

Cite this article as: Ambaw et al:: Adherence to antihypertensive treatment and associated factors among patients on follow up at University of Gondar Hospital, Northwest Ethiopia. BMC Public Health 2012 12:282.

\section{Submit your next manuscript to BioMed Central and take full advantage of:}

- Convenient online submission

- Thorough peer review

- No space constraints or color figure charges

- Immediate publication on acceptance

- Inclusion in PubMed, CAS, Scopus and Google Scholar

- Research which is freely available for redistribution 